\title{
Birmingham community mental health team for the homeless
}

\author{
Martin Commander, Sue Odell and Sashi Sashidharan
}

\begin{abstract}
Mental health services have been criticised for falling to respond to the needs of the rising number of homeless mentally ili. We report on the first year of referrals to a community mental hectth team established to meet the needs of the severely mentally ill homeless in Birmingham. Most users had a psychotic disorder and a lengthy history of unstable housing, and experienced a range of other disadvantages. Although the feam is successtully reaching its prortty group, examination of other characteristics of users has highlighted a number of issues which should inform the future planning and development of the service.
\end{abstract}

A sizeable proportion of the homeless population suffers from severe mental illness (Scott, 1993). There is growing recognition that these people are not adequately served by mainstream mental health services (House of Commons Health Committee, 1994: Mental Health Foundation. 1994; Health Advisory Service, 1995). They move frequently across community mental health team catchment area boundaries making it difficult to carry out comprehensive assessments and to provide adequate follow-up (Ritchie et al, 1994) New approaches to service delivery are required if this situation is to improve (Dixon et al, 1995).

Research in West Birmingham (a deprived multi ethnic inner-city area) estimated the six month prevalence of psychiatric morbidity among residents of communal establishments (defined as multi-occupancy accommodation for four or more people providing communal catering) at $42 \%$, half of whom were suffering from a psychotic disorder (Sashidharan et al, 1995a). Of those with mental health problems only $58 \%$ were in contact with psychiatric services. Almost two-thirds of the 170 residents interviewed had been at their current address for six months or more and it was proposed that their needs could best be met by local community mental health teams (Sashidharan et al, 1995a). However, a substantial minority were highly mobile and likely to be excluded from services providing care to residents in defined geographical areas. Largely as a result of these findings, the city-wide community mental health team for the homeless was established. It was intended that the team should focus on itinerant single homeless people, prioritising those with severe and persistent mental health problems not in contact with mainstream services.

For most of the year the team consisted of a consultant psychiatrist (0.5 FTE), three community psychiatric nurses and one resettlement officer. The service operates during office hours. Users requiring in-patient care are admitted under local consultants determined on a rota basis. Referrals are accepted from any source. but the team actively targets direct access hostels in the city. Interventions are broad based and include a strong emphasis on social aspects of care, especially assistance with finances and accommodation.

The aim of the study was to assess the introduction of the new service, to determine whether or not the team was successfully reaching its target group, and to characterise the users of the service.

\section{The study}

Although some team members were in post beforehand, the team formally commenced on 1 August 1994. Details were obtained on all people referred to the team from this date up to $31 \mathrm{July}$ 1995. A case register was established for the purpose of collecting the data and formed the basis of the team's weekly review of referrals and open cases, thus ensuring its accuracy. Only brief details were collected on those people referred who the team did not feel it appropriate to assess. For those who were seen, more extensive information covering socio-demographic, accommodation and clinical factors were obtained using a specially designed proforma. This was completed routinely by the clinical staff.

\section{Findings}

During the year 353 referrals were made to the team, representing 299 people. The majority of those referred were male $(88 \%)$ and White $(86 \%$; Black $9 \%$ and Asian 5\%), and their median age was 34 years (range 18-84). The most common source of referral was from hostel staff (Table 1). and the majority of people referred were living in 
Table 1. Source of referral

\begin{tabular}{lc}
\hline & $\%$ \\
\hline Hostal staff & 42 \\
Mental health professional & 24 \\
GP/primary care nurse & 16 \\
Self & 7 \\
Other & 10 \\
\hline
\end{tabular}

hostels (74\%). Fifty-nine per cent of referrals prompted an assessment, while $26 \%$ required advice from the team (usually about accommodation) or to be redirected to another agency such as a local community mental health team, or specialist addiction services. The remainder of those referred could not be located.

During the year 195 assessments (involving 182 people) took place. Three-quarters of these (74\%) occurred at the hostel where the person was staying. The age, gender and ethnicity of those assessed reflected those of people referred. Three-quarters $(77 \%)$ were single never having been married, and a further $19 \%$ were divorced. Only $10 \%$ of those assessed had worked in the year prior to assessment. One in ten had been in the armed forces (10\%; 95\% CI 5-17). A considerable proportion of those seen had had no contact with their family in the previous three months (49\%; 95\% CI 40-58), and one in five had been in care as a child (20\%; 95\% CI 13-28).

The high mobility of people seen was reflected in the fact that less than half had been born in Birmingham and at the time of assessment onethird had been in the city for less than three months (Table 2). Over half had been homeless for more than a year (defined as the time since

Table 2. Accommodation, forensic and psychiatric service use history

\begin{tabular}{llr}
\hline & $\%$ & $95 \%$ CI \\
\hline Accommodation & & \\
Born in Birmingham & 42 & $35-50$ \\
In Birmingham <3 months & 30 & $23-39$ \\
Homeless > 1 year & 58 & $49-66$ \\
$\quad$ Slept rough in last 3 months & 21 & $15-29$ \\
Forensic & 42 & $35-50$ \\
$\quad$ Ever in prison & 38 & $30-47$ \\
Incident involving police in & & \\
$\quad$ last 3 months & & \\
Psychiatric care & 85 & $80-90$ \\
Any previous contact with & & \\
psychiatric services & & $58-73$ \\
Any previous in-patient care & 66 & $27-42$ \\
3 or more admissions & 34 & $31-46$ \\
Any involuntary admission & 39 & $6-17$ \\
Any admission of $>1$ year & 10 & \\
\hline
\end{tabular}

they last spent six months in a private household), and one in five had slept rough at some point during the previous 3 months.

Many had a history of imprisonment and had been involved with the police during the year prior to assessment. The majority had had previous contact with psychiatric services, many including in-patient care and involving detention under the Mental Health Act (Table 2). One in ten had had spells in psychiatric hospitals lasting longer than one year. The most common diagnostic category was psychosis or manic depression, followed by substance use disorders (Table 3).

Fifty-six per cent of assessments resulted in the user being taken on for an episode of care. One in five were given advice but received no further intervention from the team. This usually involved guidance about accommodation or about other agencies that could provide appropriate help. A further $17 \%$ were referred directly to another agency, usually to addiction services, or to mental health services with whom they were found already to be receiving on-going care. No further contact was made with a small number of people as they could not be located.

There were 110 care episodes during the year (involving 105 people). People taken on for care were more likely to have a psychotic disorder and a previous history of psychiatric care, but otherwise presented with similar characteristics to those described above. The majority had severe mental illness (59\%) but a substantial minority had primary drug and alcohol problems (13\%). Furthermore, one in five users with severe mental illness had a subsidiary diagnosis of a substance use disorder.

\section{Comment}

This paper examines the implementation of a new service for severely mentally ill homeless people in Birmingham. It does not assess the effectiveness of the interventions provided or, for example, the role of in-patient care, which will be the subject of future reports. The data demonstrate that the team has become successfully integrated into the network of services for homeless people in Birmingham. However, certain groups were under-represented within the service. There were fewer women than might have been expected on

Table 3. Diagnoses of those assessed by the team

\begin{tabular}{ll}
\hline & $\%$ \\
\hline Psychosis/manic depression & 42 \\
Substance use & 23 \\
Other diagnosis & 31 \\
\hline
\end{tabular}


the basis of the numbers reported in studies of single homeless populations (Anderson et al, 1993). This is probably because the team does not target women's refuges or the housing department's emergency accommodation where many homeless women and families stay. Ethnic minorities were also under-represented in referrals to the team, relative to their proportion in the local population. This is in contrast to the overrepresentation of black people with severe mental illness within psychiatric services (Sashidharan et al, 1995b). It is possible that blacks are less likely than whites to become homeless (or to have prolonged periods of homelessness) but equally it may be that on becoming homeless they are using other accommodation and agencies which the team do not currently target.

The team does not prioritise people with substance use disorders but the need for services for homeless people with such problems was evident. Approximately one in five referrals simply offered advice or redirected to other agencies involved drug and alcohol problems, and a similar proportion of those assessed had a primary diagnosis of substance use disorder. Delays in obtaining appointments with local addiction services coupled with the lack of outreach services and options for community detoxification resulted in the team providing treatment to some people with primary substance use problems. In addition, the presentation of those seen with other diagnoses was often complicated by coexisting drug and alcohol problems.

It would appear that the team is effectively targeting a transient population with severe psychiatric morbidity who are detached from existing mental health services. A large proportion have had previous contact with services, including admissions to hospital under the Mental Health Act. They are highly mobile and many have a long history of homelessness. They move frequently not only between different residences and sleeping rough, but also between cities. They are socially disadvantaged, having multiple impairments and difficulties in addition to their mental health and housing problems. Often they have little employment experience and are isolated from their families. Many also exhibit a recurrent pattern of institutional living which includes not only frequent and sometimes prolonged psychiatric admissions but also time spent in local authority care as children, spells in the armed forces and extensive periods of imprisonment. These characteristics are similar to those of users of the homeless mentally ill initiative teams in London (Craig et al, 1995), and highlight the importance of engaging this neglected population.

\section{References}

ANDERson, I., KEMP, P. \& QUILGARS, D. (1993) Single Homeless People. London: HMSO.

Craig, T. Bayuss, E. Kiein, O. et al (1995) The Homeless Mentally II Initiative: An Evaluation of Four Clinical Teams. London: Department of Health.

Dixon, L. B., KRAUSS, N., KERNAN, E., et al (1995) Modifying the PACT model to serve homeless people with severe mental illness. Psychiatric Services, 46, 684-688.

Health AdVisory Service (1995) People who are Homeless: Mental Health Services a Place in Mind. London: HMSO.

House of Commons Health Committee (1994) Creating Communtty Care. London: Mental Health Foundation.

Mental Health Foundation (1994) Creating Community Care. London: MHF.

RrTchIE, J., Dick, D. \& Lngham, R. (1994) The Report into the Inquiry into the Care and Treatment of Christopher Clunis. London: HMSO.

SAshidharan, S. P., Commander, M. J., ODEL, S. M., et al (1995a) West Btrmingham Epidemiology Survey - A Survey of Communal Establishments. Birmingham: Untversity of Birmingham.

Sashidharan, S. P., Commander, M. J., Odeu, S. M., et al (1995b) West Btrmingham Epidemiology Survey - Use of Specialist Mental Health Services. Birmingham: Untversity of Birmingham.

ScoTT, J. (1993) Homelessness and mental illness. Brttish Journal of Psychiatry. 162, 314-324.

*Martin Commander, Sue Odell, and Sashi Sashidharan, University of Birmingham, Department of Psychiatry. Northern Birmingham Mental Health (NHS) Trust, Academic Unit, 71 Fentham Road, Erdington, Birmingham B23 6AL

*Correspondence 